\title{
Pengaruh Penggunaan Buku Saku oleh Motivator terhadap Pengetahuan dan Keterampilan Motivator dalam Mengatasi Permasalahan Pemberian ASI (di Kecamatan Sewon Kabupaten Bantul)
}

\author{
Nur Indah Rahmawati ${ }^{1}$, Sri Achadi Nugraheni ${ }^{2}$, Atik Mawarni ${ }^{3}$ \\ ${ }^{1}$ Sekolah Tinggi Ilmu Kesehatan Alma Ata Yogyakarta \\ Jalan Ringroad Barat Daya No 1 Tamantirto, Kasihan, Bantul, Yogyakarta \\ 2,3 Universitas Diponegoro Semarang JI. Ngumpulsari Raya No.12, Tembalang, \\ Kota Semarang, Jawa Tengah 50277
}

\begin{abstract}
Abstrak
Cakupan ASI Eksklusif di Kecamatan Sewon masih rendah, salah satunya karena kurang optimalnya peran motivator kegiatan kelompok pendamping $(K P)$ ibu. Motivator kurang percaya diri dalam menangani permasalahan pemberian ASI. Tujuan penelitian adalah menganalisis pengaruh penggunaan buku saku oleh motivator terhadap pengetahuan dan keterampilan motivator dalam menghadapi masalah pemberian ASI Eksklusif di Kecamatan Sewon Kabupaten Bantul. Penelitian ini merupakan pre eksperimen dengan rancangan nonequivalent one group pre test and post test design. Populasi adalah Motivator KP ibu di Kecamatan Sewon sebanyak 50 orang. Pengambilan data melalui kuesioner dan observasi kemudian dilakukan analisis univariat (deskriptif), bivariat (Paired $T$ test). Hasil penelitian menunjukkan bahwa umur responden rata-rata 46,74 tahun. Pendidikan responden sebagian besar adalah SMA yaitu 25 orang, responden sebagian besar tidak bekerja yaitu 31 orang (62\%). Pengetahuan motivator sebelum dilakukan pelatihan penggunaan buku saku nilai rata-ratanya adalah 64,5 sedangkan nilai setelah dilakukan pelatihan reratanya adalah 72,1. Keterampilan motivator pada saat pretest nilai reratanya adalah 57,6 sedangkan pada posttest nilai reratanya adalah 64,65. Terdapat pengaruh penggunaan buku saku kelompok pendukung ibu tentang permasalahan dalam pemberian ASI pada variabel pengetahuan ( $p$-value $=0,0001$ ) artinya penggunaan buku saku mempengaruhi pengetahuan motivator dalam permasalahan pemberian ASI. Disarankan untuk Dinas Kesehatan dan Puskesmas agar dapat mengembangkan pelatihan untuk motivator sebagai penyegaran (refresh) sehingga meningkatkan pengetahuan dan keterampilan motivator dalam permasalahan pemberian ASI sehingga dapat meningkatkan cakupan ASI Eksklusif.
\end{abstract}

Kata Kunci: buku saku, keterampilan, motivator KP, pengetahuan

\section{Influence of Handbook Uses by Motivator on Knowledge and Skills in Solving Problems of Breastfeeding (in District of Sewon Bantul)}

\begin{abstract}
Coverage of exclusive breastfeeding in the District of Sewon still low, either because they are less optimal role of KP motivator. They lack of confidence in dealing with problems in breastfeeding. The research objective was to analyze the effect of the use of a handbook by the motivator of the knowledge and skills motivator in dealing with problems in exclusive breastfeeding in the District of Sewon Bantul. This research is pre experiment with the design of nonequivalent one group pre test and post test design. The population was Motivator KP Capital in District Sewon many as 50 people. Collecting data through questionnaires and observations then performed univariate analysis (descriptive), bivariate (Paired $T$ test). The results of research showed that the respondent's average age was 46.74. Education respondents mostly high school was 25 people, most of the respondents did not work that 31 people (62\%). Motivator knowledge prior to intervention use a pocket book value of the average was 64,5 while the value after the intervention mean value is 72.1. Motivator skills during pretest score was 57.6 at, while the second posttest mean value is 64.65. There was the effect of using a pocket book support group of mothers about breastfeeding, the problem of skills variable ( $p$-value $=0.0001)$ means the use of a paperback book motivators influencing
\end{abstract}


skills in breastfeeding issues. Suggested for Health Department and Community Health Center in order to develop a motivator as refresher training for, to improve the knowledge and skills motivator in breastfeeding issues so as to increase the coverage of exclusive breastfeeding.

Keywords: motivator KP, pocket books, knowledge, skills

Info Artikel:

Artikel dikirim pada 7 Juni 2015

Artikel diterima pada 7 Juni 2015

\section{PENDAHULUAN}

Salah satu pendukung keberhasilan ibu menyusui yang dapat meningkatkan cakupan pemberian ASI ekslusif dalam rangka menurunkan Angka Kematian Bayi (AKB) tertuang dalam kebijakan 10 Langkah Menuju Keberhasilan Menyusui (LMKM), yaitu mengupayakan terbentuknya Kelompok Pendukung ASI di masyarakat dan merujuk ibu kepada kelompok tersebut ketika pulang dari Rumah Sakit/Rumah Bersalin/Sarana Pelayanan Kesehatan(1).

Kabupaten Bantul telah membuat Kelompok Pendukung (KP) Ibu sejak tahun 2009, namun pelaksanaannya masih kurang efektif di dalam pencapaian peningkatan cakupan ASI Ekskluif. Ini terbukti dimana tahun 2009 cakupan ASI eksklusif Bantul $32,5 \%$ sedangkan tahun 2010 sebesar $29,87 \%$, 2011 sebesar $42,3 \%$, tahun 2012 sebesar $63,51 \%$ sedangkan tahun 2013 62,05\% masih di bawah dari target minimal nasional yakni 80\%. Kecamatan Sewon, pada tahun 2013 merupakan kecamatan dengan cakupan ASI eksklusif terendah, dimana Puskesmas Sewon I 26,14\%, sedangkan Puskesmas Sewon II $67,84 \%(2)$.

Kemampuan motivator dalam membantu para ibu agar sukses menyusui secara optimal perlu ditingkatkan melalui pelatihan dan penggunaan alat peraga maupun buku pedoman motivator dalam bentuk buku saku. Hal ini dikarenakan motivator kurang percaya diri dalam menangani kasus yang sulit dan memerlukan bantuan dari pembina motivator untuk menyelesaikan masalah yang terjadi. Dengan menggunakan buku saku diharapkan motivator menjadi lebih percaya diri dalam melakukan panduan dalam kegiatan Kelompok Pendukung (KP) lbu dikarenakan pengetahuan serta pemahamannya tentang ASI eksklusif meningkat.

Motivator dalam melaksanakan kegiatannya dilengkapi oleh buku-buku panduan yang telah disiapkan, seperti Modul Panduan Motivator, Panduan Pelatihan Motivator dan 10 Topik Umum Diskusi Kelompok Pendukung Ibu. Pada ketiga buku yang sudah tersedia ini, tidak ada, materi mengenai permasalahan dalam memberikan ASI, sehingga menyebabkan motivator tidak bisa menjawab pertanyaan dari para anggotanya. Buku saku adalah buku berukuran kecil yang dapat dimasukkan ke dalam saku dan mudah dibawa ke mana-mana(3).

\section{BAHAN DAN METODE}

Jenis penelitian yang digunakan adalah pre eksperimen dengan rancangan one group pre test and post test design, yaitu sebuah desain penelitian yang digunakan dengan cara memberikan tes awal dan tes akhir terhadap sampel penelitian kelompok tunggal(4). Desain ini dilakukan untuk mengetahui pengaruh penggunaan buku saku Kelompok Pendukung (KP) Ibu terhadap pengetahuan dan keterampilan motivator dalam menghadapi masalah dalam pemberian ASI eksklusif. Populasi penelitian adalah motivator KP Ibu Kecamatan Sewon sebanyak 50. Variabel bebas adalah pengetahuan dan keterampilan sedangkan variabel terikat adalah penggunaan buku saku KP ibu. Pengumpulan data menggunakan kuesioner dan lembar observasi. Analisis data menggunakan analisis univariat (distribusi frekuensi), analisis bivariat (uji paired T Test).

\section{HASIL DAN BAHASAN}

Rata-rata umur responden didapatkan bahwa rata-rata umur 46,74 tahun, dimana umur $>46,74$ tahun sebanyak $52 \%$ sedangkan umur $\leq 46,74$ sebanyak $48 \%$. Dilihat dari aspek pendidikan, bahwa sebagian besar adalah berpendidikan SMA yaitu sebanyak $50 \%$ dan paling sedikit berpendidikan SD yaitu 12 orang. Tingkat pendidikan motivator Kelompok Pendukung Ibu di Kecamatan Sewon mayoritas adalah berpendidikan SMA. Terdapat 1 orang motivator yang berijazah S2. Dilihat dari pekerjaan, mayoritas kader tidak bekerja yaitu sebanyak $62 \%$, motivator yang bekerja hanya $38 \%$. Mayoritas motivator tidak bekerja, motivator yang bekerja bermata pencaharian sebagai buruh, guru Paud, penjahit, dan pemilik sekolah.

Tabel 1 menunjukkan sebelum dilakukan pelatihan penggunaan buku saku pengetahuan motivator yang kurang terdapat pada item soal 
permasalahan menyusui yang terjadi pada saat hamil (56\%), BAB pada bayi (62\%), gejala dari payudara bengkak $(62 \%)$, cara mengatasi payudara bengkak (54\%), penanganan radang payudara (64\%), gejala dari radang payudara (58\%), solusi pada ibu bekerja (64\%), kondisi ibu bisa memberikan ASI (68\%), penanganan puting susu nyeri $(40 \%)$, ibu bekerja tetap bisa menyusui (58\%), penyimpanan ASI
Perahan pada soal no 18, 19, dan 20 (62\%, 60\%, dan 58\%).

Setelah dilaksanakannya pelatihan penggunan buku saku selama dua kali, untuk mengetahui pengetahuan motivator dilakukan posttest. Berikut gambaran pengetahuan motivator saat posttest.

Tabel 2 menunjukkan bahwa setelah dilakukan intervensi sebanyak dua kali yakni selama dua kali

Tabel 1. Distribusi Frekuensi Pengetahuan Motivator saat Pretest

\begin{tabular}{|c|c|c|c|c|}
\hline \multirow{2}{*}{ Pertanyaan } & \multicolumn{4}{|c|}{ Jawaban } \\
\hline & Benar & $\%$ & Salah & $\%$ \\
\hline Permasalahan menyusui yang terjadi pada saat hamil & 28 & 56 & 22 & 44 \\
\hline BAB bayi encer dan sehari bisa $2-3$ kali. & 31 & 62 & 19 & 38 \\
\hline Penyebab dari puting susu lecet & 36 & 72 & 14 & 28 \\
\hline Kondisi puting susu datar & 43 & 86 & 7 & 14 \\
\hline Penanganan yang tepat pada puting susu yang lecet & 36 & 72 & 14 & 28 \\
\hline Gejala dari payudara bengkak & 31 & 62 & 19 & 38 \\
\hline Cara mengatasi payudara bengkak & 27 & 54 & 23 & 46 \\
\hline Pengertian dari mastitis & 37 & 74 & 13 & 26 \\
\hline Penanganan pada radang payudara & 32 & 64 & 18 & 36 \\
\hline Gejala dari radang payudara & 29 & 58 & 21 & 42 \\
\hline Tanda ASI benar-benar kurang & 38 & 76 & 12 & 24 \\
\hline Solusi pada ibu bekerja yang masih tetap ingin meneruskan menyusui & 32 & 64 & 18 & 36 \\
\hline ASI tidak diberikan pada bayi & 35 & 70 & 15 & 30 \\
\hline Kondisi ibu untuk memberikan ASI & 34 & 68 & 16 & 32 \\
\hline Kondisi diperbolehkan melakukan IMD & 37 & 74 & 13 & 26 \\
\hline Penanganan dari puting susu ibu yang nyeri & 20 & 40 & 30 & 60 \\
\hline Ibu bekerja agar tetap bisa menyusui bayinya, & 29 & 58 & 21 & 42 \\
\hline Penyimpanan ASI Perahan & 31 & 62 & 19 & 38 \\
\hline Penyimpanan ASI Perahan & 30 & 60 & 20 & 40 \\
\hline Penyimpanan ASI Perahan & 29 & 58 & 21 & 42 \\
\hline
\end{tabular}

Tabel 2. Distribusi Frekuensi Pengetahuan Motivator saat Posttest

\begin{tabular}{lcccc}
\hline \multicolumn{1}{c}{ Pertanyaan } & \multicolumn{3}{c}{ Jawaban } \\
\cline { 2 - 5 } Permasalahan menyusui yang terjadi pada saat hamil & Benar & $\%$ & Salah & $\%$ \\
BAB bayi encer sehari bisa 2-3 x & 27 & 54 & 23 & 46 \\
Penyebab dari puting susu lecet & 32 & 64 & 18 & 36 \\
Kondisi puting susu datar & 36 & 72 & 14 & 28 \\
Penanganan yang tepat pada puting susu yang lecet & 44 & 88 & 6 & 12 \\
Gejala dari payudara bengkak & 36 & 72 & 14 & 28 \\
Cara mengatasi payudara bengkak & 31 & 62 & 19 & 38 \\
Pengertian dari mastitis & 26 & 52 & 24 & 48 \\
Penanganan pada radang payudara & 37 & 74 & 13 & 26 \\
Gejala dari radang payudara & 34 & 68 & 16 & 32 \\
Tanda ASI benar-benar kurang & 32 & 64 & 18 & 36 \\
Solusi pada ibu bekerja yang masih tetap ingin meneruskan menyusui & 39 & 78 & 11 & 22 \\
ASI tidak diberikan pada bayi & 37 & 74 & 13 & 26 \\
Kondisi ibu untuk memberikan ASI & 44 & 88 & 6 & 12 \\
Kondisi diperbolehkan melakukan IMD & 43 & 86 & 7 & 14 \\
Penanganan dari puting susu ibu yang nyeri & 42 & 84 & 8 & 16 \\
Ibu bekerja agar tetap bisa menyusui bayinya, & 24 & 48 & 26 & 52 \\
Penyimpanan ASI Perahan & 37 & 74 & 13 & 26 \\
Penyimpanan ASI Perahan & 42 & 84 & 8
\end{tabular}


dalam dua minggu berturut-turut masih terdapat pengetahuan yang kurang yaitu pada item soal permasalahan menyusui pada saat hamil (56\%), cara mengatasi payudara bengkak (54\%), serta cara mengatasi puting susu yang nyeri (48\%).

Tabel 3 menunjukkan bahwa keterampilan saat pretest yang paling banyak dimiiki oleh motivator adalah keterampilan tentang memperkenalkan diri dan menyepakati ketentuan-ketentuan dalam KP lbu dengan motivator yang melakukan dengan sempurna sebanyak 50 orang (100\%), sedangkan keterampilan yang kurang adalah mengenai keterampilan mengemukakan tujuan peserta diundang, manfaat menghadiri pertemuan, menceritakan hal-hal yang menarik yang dialami motivator, menulis kesepakatankesepakatan, menawarkan topik diskusi dan relaksasi yaitu dengan tidak ada motivator yang melakukan keterampilan tersebut $(0 \%)$.

Setelah dilaksanakannya pelatihan penggunan buku saku selama dua kali, untuk mengetahui keterampilan motivator dilakukan posttest. Gambaran keterampilan motivator saat posttes di sajikan pada Tabel 4.
Tabel 4 menunjukkan bahwa keterampilan yang paling banyak dimiiki oleh motivator adalah keterampilan tentang memperkenalkan diri dan menyepakati ketentuan-ketentuan dalam KP Ibu dengan motivator yang melakukan dengan sempurna sebanyak 50 orang $(100 \%)$, sedangkan keterampilan yang kurang adalah mengenai keterampilan mengemukakan tujuan peserta diundang, menceritakan hal-hal yang menarik yang dialami motivator, menulis kesepakatankesepakatan, menawarkan topik diskusi dan relaksasi yaitu dengan tidak ada motivator yang melakukan keterampilan tersebut $(0 \%)$.

Berdasarkan hasil analisis pada Tabel 5 terlihat bahwa nilai rata-rata pengetahuan motivator sebelum dilakukan intervensi adalah 64,5 dengan median 65,0 dan standar deviasi 9,4356 dengan nilai terendah adalah 45 dan nilai tertinggi adalah 90 . Sedangkan nilai rata-rata pengetahuan motivator sesudah dilakukan intervensi adalah 72,1 dengan median 70,00 dan standar deviasi 8,86923 dengan nilai terendah adalah 55 dan nilai tertinggi adalah 95 .

Tabel 3. Distribusi Frekuensi Keterampilan saat Pretest

\begin{tabular}{|c|c|c|c|c|c|c|}
\hline \multirow{2}{*}{ Pernyataan } & \multicolumn{6}{|c|}{ Keterampilan } \\
\hline & TD & $\%$ & DTS & $\%$ & DS & $\%$ \\
\hline \multicolumn{7}{|l|}{ Pembukaan } \\
\hline Memperkenalkan diri dan menjelaskan perannya sebagai motivator & 0 & 0 & 0 & 0 & 50 & 100 \\
\hline Menjelaskan apa tujuan peserta diundang & 0 & 0 & 50 & 100 & 0 & 0 \\
\hline Menjelaskan manfaat menghadiri pertemuan & 0 & 0 & 50 & 100 & 0 & 0 \\
\hline Menjelaskan pertemuan KP Ibu akan dilaksanakan secara rutin & 43 & 86 & 6 & 12 & 1 & 2 \\
\hline Menjelaskan bahwa setiap pertemuan dilaksanakan 2 jam & 0 & 0 & 2 & 4 & 48 & 96 \\
\hline Memperkenalkan peserta untuk saling mengenalkan diri & 36 & 72 & 7 & 14 & 7 & 14 \\
\hline \multicolumn{7}{|l|}{ Membangun Keakraban } \\
\hline Motivator meminta peserta untuk menceritakan paling menarik & 31 & 62 & 8 & 16 & 11 & 22 \\
\hline $\begin{array}{l}\text { Motivator meminta peserta untuk menceritakan hal-hal yang paling } \\
\text { menarik baik seputar kehamilan, menyusui }\end{array}$ & 1 & 2 & 2 & 4 & 47 & 94 \\
\hline Motivator menceritakan hal-hal yang menarik yang dialami motivator. & 0 & 0 & 50 & 100 & 0 & 0 \\
\hline Menyepakati ketentuan-ketentuan dalam kegiatan KP Ibu. & 0 & 0 & 0 & 0 & 50 & 100 \\
\hline Menulis kesepakatan-kesepakatan dalam kegiatan KP & 0 & 0 & 50 & 100 & 0 & 0 \\
\hline \multicolumn{7}{|l|}{ Pengumuman dan Perayaan } \\
\hline Mengumumkan informasi-informasi yang berguna & 1 & 2 & 1 & 2 & 48 & 96 \\
\hline Merayakan perubahan yang terjadi pada anggota kelompok & 0 & 0 & 3 & 6 & 47 & 94 \\
\hline \multicolumn{7}{|l|}{ Diskusi } \\
\hline Motivator menawarkan suatu topik untuk diskusi & 0 & 0 & 50 & 100 & 0 & 0 \\
\hline Membuat pertanyaan terbuka untuk membuka & 23 & 46 & 12 & 24 & 15 & 30 \\
\hline Mengingatkan peserta jika waktu sudah terpakai satu setengah jam, & 26 & 52 & 12 & 24 & 12 & 24 \\
\hline Relaksasi seperti senam hamil/peregangan-peregangan otot & 1 & 2 & 49 & 98 & 0 & 0 \\
\hline \multicolumn{7}{|l|}{ Kesimpulan } \\
\hline Motivator menutup pertemuan & 3 & 6 & 46 & 92 & 1 & 2 \\
\hline Motivator menyampaikan rangkuman pertanyaan & 2 & 4 & 47 & 94 & 1 & 2 \\
\hline Membuat kesepakatan mengenai : tanggal, tempat dan topik & 31 & 62 & 10 & 20 & 9 & 18 \\
\hline
\end{tabular}

Keterangan TD: Tidak dilakukan; DTS: Dilakukan tidak sempurna; DS: Dilakukan Sempurna 
Tabel 4. Distribusi Frekuensi Keterampilan Motivator saat Posttest

\begin{tabular}{|c|c|c|c|c|c|c|}
\hline \multirow{2}{*}{ Pernyataan } & \multicolumn{6}{|c|}{ Keterampilan } \\
\hline & TD & $\%$ & DTS & $\%$ & DS & $\%$ \\
\hline \multicolumn{7}{|l|}{ Pembukaan } \\
\hline Memperkenalkan diri dan menjelaskan perannya sebagai motivator & 0 & 0 & 0 & 0 & 50 & 100 \\
\hline Menjelaskan apa tujuan peserta diundang & 0 & 0 & 50 & 100 & 0 & 0 \\
\hline Menjelaskan manfaat menghadiri pertemuan & 0 & 0 & 47 & 94 & 3 & 6 \\
\hline Menjelaskan pertemuan KP Ibu akan dilaksanakan secara rutin & 9 & 18 & 28 & 56 & 13 & 26 \\
\hline Menjelaskan bahwa setiap pertemuan dilaksanakan 2 jam & 0 & 0 & 2 & 4 & 48 & 96 \\
\hline Memperkenalkan peserta untuk saling mengenalkan diri & 15 & 30 & 26 & 52 & 9 & 18 \\
\hline \multicolumn{7}{|l|}{ Membangun Keakraban } \\
\hline Motivator meminta peserta untuk menceritakan paling menarik & 18 & 36 & 19 & 38 & 13 & 26 \\
\hline $\begin{array}{l}\text { Motivator meminta peserta untuk menceritakan hal-hal yang paling } \\
\text { menarik baik seputar kehamilan, menyusui }\end{array}$ & 1 & 2 & 3 & 6 & 46 & 96 \\
\hline Motivator menceritakan hal-hal yang menarik yang dialami motivator. & 0 & 0 & 49 & 98 & 1 & 2 \\
\hline Menyepakati ketentuan-ketentuan dalam kegiatan KP lbu. & 0 & 0 & 1 & 2 & 49 & 98 \\
\hline Menulis kesepakatan-kesepakatan dalam kegiatan KP & 0 & 0 & 48 & 96 & 2 & 4 \\
\hline \multicolumn{7}{|l|}{ Pengumuman dan Perayaan } \\
\hline Mengumumkan informasi-informasi yang berguna & 0 & 0 & 1 & 2 & 49 & 98 \\
\hline Merayakan perubahan pada anggota kelompok & 0 & 0 & 4 & 8 & 46 & 92 \\
\hline \multicolumn{7}{|l|}{ Diskusi } \\
\hline Motivator menawarkan suatu topik untuk diskusi & 0 & 0 & 50 & 100 & 0 & 0 \\
\hline Membuat pertanyaan terbuka untuk membuka & 8 & 16 & 20 & 40 & 22 & 44 \\
\hline Mengingatkan peserta jika waktu sudah terpakai satu setengah jam, & 8 & 16 & 19 & 38 & 23 & 46 \\
\hline Relaksasi seperti senam hamil/peregangan-peregangan otot & 1 & 2 & 49 & 98 & 0 & 0 \\
\hline \multicolumn{7}{|l|}{ Kesimpulan } \\
\hline Motivator menutup pertemuan & 3 & 6 & 44 & 88 & 3 & 6 \\
\hline Motivator menyampaikan rangkuman pertanyaan & 1 & 2 & 48 & 96 & 1 & 2 \\
\hline Membuat kesepakatan mengenai : tanggal, tempat dan topik & 19 & 38 & 18 & 36 & 13 & 26 \\
\hline
\end{tabular}

Keterangan TD: Tidak dilakukan; DTS: Dilakukan tidak sempurna; DS: Dilakukan Sempurna

Tabel 5. Ukuran Tendency Central dan Penyebaran Pengetahuan Motivator tentang Pemberian ASI

\begin{tabular}{lccccc}
\hline Variabel & Mean & Median & SD & Min & Maks \\
\hline Pre Test & 64,5 & 65,0 & 9,4356 & 45 & 90 \\
Post Test & 72,1 & 70,00 & 8,86923 & 55 & 95 \\
\hline
\end{tabular}

Tabel 6. Ukuran Tendency Central dan Penyebaran Keterampilan Motivator tentang Pemberian ASI

\begin{tabular}{lccccc}
\hline Variabel & Mean & Median & SD & Min & Maks \\
\hline Pre Test & 57,6 & 57,5 & 8,24 & 42,5 & 75 \\
Post Test & 64,65 & 65 & 7,11 & 47,5 & 82,5 \\
\hline
\end{tabular}

Berdasarkan hasil analisis pada Tabel 6 terlihat bahwa nilai rata-rata keterampilan motivator sebelum dilakukan intervensi adalah 57,6 dengan median 57,5 dan standar. Sedangkan nilai rata-rata keterampilan motivator sesudah dilakukan intervensi adalah 64,65 dengan median 65 dan standar deviasi 7,11 dengan nilai terendah adalah 47,5 dan nilai tertinggi adalah 82,5.
Tabel 7 menunjukkan bahwa rerata skor pengetahuan pretest dan posttest menunjukkan ada perbedaan yang signifikan $(p<0,05)$. Terdapat peningkatan rerata skor pengetahuan motivator sebelum dan sesudah pelatihan penggunaan buku saku.

Tabel 8 menunjukkan bahwa rerata skor keterampilan pre-test dan post-test menunjukkan ada perbedaan yang signifikan $(p<0,05)$. Terdapat peningkatan rerata skor keterampilan motivator sebelum dan sesudah pelatihan penggunaan buku saku.

Hasil analisis statistik rerata skor keterampilan menunjukkan ada perbedaan bermakna antara sebelum dilakukan intervensi dan sesudah dilakukan intervensi. Berdasarkan analisis bivariat keterampilan kader tentang penggunaan metode buku saku tentang permasalahan dalam pemberian ASI, terdapat perbedaan nilai rerata antara sebelum dan setelah dilakukan intervensi dengan buku saku. Pada saat pre-test (sebelum dilakukan intervensi dengan

Tabel 7. Perbedaan Pengetahuan Motivator Sebelum dan sesudah pelatihan

\begin{tabular}{ccccc}
\hline Variabel & $\begin{array}{c}\text { Nilai Rata-rata Sebelum } \\
\text { Intervensi } \pm \text { SD }\end{array}$ & $\begin{array}{c}\text { Nilai Rata-rata Sesudah } \\
\text { Intervensi } \pm \text { SD }\end{array}$ & Selisih Rata-rata \pm SD & $\begin{array}{c}\text { Nilai } p \\
\text { Paired T Test }\end{array}$ \\
\hline Pengetahuan & $64,5 \pm 9,44$ & $72,1 \pm 8,869$ & $-7,6 \pm 3,223$ & 0,0001 \\
\hline
\end{tabular}


Tabel 8. Perbedaan Rerata Skor Keterampilan Sebelum dan Sesudah Pelatihan Pada Saat Post Test

\begin{tabular}{ccccc}
\hline Variabel & $\begin{array}{c}\text { Nilai Rata-rata Sebelum } \\
\text { Intervensi } \pm \text { SD }\end{array}$ & $\begin{array}{c}\text { Nilai Rata-rata Sesudah } \\
\text { Intervensi II } \pm \text { SD }\end{array}$ & Selisih Rata-rata \pm SD & $\begin{array}{c}\text { Nilai } p \\
\text { Paired T Test }\end{array}$ \\
\hline Keterampilan & $57,6 \pm 8,23$ & $64,65 \pm 7,11$ & $-7,05 \pm 4,155$ & 0,0001 \\
\hline
\end{tabular}

menggunakan buku saku) nilai mean 57,6. Pada saat post-test (setelah dilakukan intervensi menggunakan buku saku) pada saat posttest nilai mean nya menjadi 64,65 . Hal ini menunjukkan terjadi peningkatan keterampilan responden tentang permasalahan dalam pemberian ASI sebelum dan setelah dilakukan intervensi dengan menggunakan buku saku.

Hasil analisis statistik rerata skor pengetahuan menunjukkan ada perbedaan bermakna antara sebelum dilakukan intervensi dan sesudah dilakukan intervensi. Berdasarkan analisis bivariat pengetahuan kader tentang penggunaan metode buku saku tentang permasalahan dalam pemberian ASI, terdapat perbedaan nilai rerata antara sebelum dan setelah dilakukan intervensi dengan buku saku. Pada saat pre-test (sebelum dilakukan intervensi dengan menggunakan buku saku) nilai mean 64,5 . Pada saat post-test (setelah dilakukan intervensi menggunakan buku saku) nilai mean nya 72,1 . Hal ini menunjukkan terjadi peningkatan pengetahuan responden tentang permasalahan dalam pemberian ASI sebelum dan setelah dilakukan intervensi dengan menggunakan buku saku.

Nilai probabilitas dari uji paired $T$ test adalah $0,0001(0,00<0,05)$ maka Ha diterima dan Ho ditolak. Hal ini menunjukan bahwa intervensi dengan menggunakan metode buku saku tentang permasalahan dalam pemberian ASI di Kecamatan Sewon Kabupaten Bantul menyebabkan tingkat pengetahuan berbeda (meningkat) dibandingkan sebelum diberikan intervensi dengan menggunakan buku saku. Ini berarti penggunaan buku saku berpengaruh terhadap peningkatan pengetahuan tentang permasalahan dalam pemberian ASI di Kecamatan Sewon Kabupaten Bantul.

Pemberian buku saku mengenai jajanan sehat dapat meningkatkan pengetahuan pada responden(5). Perubahan pengetahuan tersebut dapat dilihat dari hasil selisih antara rerata pengetahuan awal dan pengetahuan akhir responden. Pada kelompok intervensi nilai perubahan atau selisih rerata pengetahuan akhir dan awal sebesar 2,025. Ada pengaruh pemberian modul tentang gizi anak terhadap peningkatan pengetahuan responden. Pemberian media berupa modul meningkatkan rerata pengetahuan responden dari 17,93 menjadi 20,13 dengan perbedaan skor 2,20(6).

Fungsi media dalam pendidikan adalah sebagai alat peraga untuk menyampaikan informasi atau pesan pesan tentang kesehatan(7). Buku saku yang diberikan berisi tentang materi gizi seimbang yang didukung oleh gambar dengan ukuran 11x8 cm. Buku saku merupakan buku dengan ukuran kecil seukuran saku sehingga efektif untuk dibawa kemana mana dan dapat dibaca kapan saja pada saat dibutuhkan, dengan keefektifan buku saku tersebut siswa dapat memperoleh pengetahuan mengenai gizi.

Media cetak merupakan media yang paling dekat dengan siswa. Materi cetak juga menempati posisi penting dalam pendidikan kesehatan karena memberikan pesan jelas yang dapat dibawa kerumah. Materi itu efektif dalam memperkuat informasi yang disampaikan secara lisan ataupun bila memang digunakan sebagai media untuk menyampaikan informasi itu sendiri(8).

Media digunakan dalam kegiatan pembelajaran karena memiliki kemampuan untuk menyajikan peristiwa yang kompleks dan rumit menjadi lebih sistematik dan sederhana, meningkatkan daya tarik dan perhatian pembelajar, dan meningkatkan sistematika pembelajaran(9). Pada penelitian ini didapatkan data bahwa hasil pengetahuan yang masih kurang pada pengetahuan tentang penyimpanan ASI Perahan pada ibu bekerja. Pemberian buku saku mengenai jajanan sehat dapat meningkatkan pengetahuan pada responden ${ }^{5}$. Perubahan pengetahuan tersebut dapat dilihat dari hasil selisih antara rerata pengetahuan awal dan pengetahuan akhir responden. Pada kelompok intervensi nilai perubahan atau selisih rerata pengetahuan akhir dan awal sebesar 2,025. Ada pengaruh pemberian modul tentang gizi anak terhadap peningkatan pengetahuan responden. Pemberian media berupa modul meningkatkan rerata pengetahuan responden dari 17,93 menjadi 20,13 dengan perbedaan skor 2,20(6).

Fungsi media dalam pendidikan adalah sebagai alat peraga untuk menyampaikan informasi atau pesan pesan tentang kesehatan(7). Buku saku yang diberikan berisi tentang materi gizi seimbang yang didukung oleh gambar dengan ukuran $11 \times 8 \mathrm{~cm}$. Buku saku merupakan buku dengan ukuran kecil seukuran saku sehingga efektif untuk di bawa kemana mana dan dapat dibaca kapan saja pada saat dibutuhkan, dengan keefektifan buku saku tersebut siswa dapat memperoleh pengetahuan mengenai gizi.

Hasil analisis statistik rerata skor keterampilan menunjukkan ada perbedaan bermakna antara 
sebelum dilakukan intervensi dan sesudah dilakukan intervensi. Berdasarkan analisis bivariat keterampilan kader tentang penggunaan metode buku saku tentang permasalahan dalam pemberian ASI, terdapat perbedaan nilai rerata antara sebelum dan setelah dilakukan intervensi dengan buku saku. Pada saat pre-test (sebelum dilakukan intervensi dengan menggunakan buku saku) nilai mean 57,6 . Pada saat post-test (setelah dilakukan intervensi menggunakan buku saku) pada saat posttest nilai mean nya menjadi 64,65 . Hal ini menunjukkan terjadi peningkatan keterampilan responden tentang permasalahan dalam pemberian ASI sebelum dan setelah dilakukan intervensi dengan menggunakan buku saku.

Nilai probabilitas dari uji paired $T$ test adalah 0,00 $(0,00<0,05)$ maka Ha diterima dan Ho ditolak. Hal ini menunjukan bahwa intervensi dengan menggunakan metode buku saku tentang permasalahan dalam pemberian ASI di Kecamatan Sewon Kabupaten Bantul menyebabkan tingkat keterampilan berbeda (meningkat) dibandingkan sebelum diberikan intervensi dengan menggunakan buku saku. Ini berarti penggunaan buku saku berpengaruh terhadap peningkatan keterampilan tentang permasalahan dalam pemberian ASI di Kecamatan Sewon Kabupaten Bantul.

Menurut Depkes, keterampilan dikatakan baik dan berhasil jika tingkat kepatuhannya mencapai 80 persen atau lebih(10). Berdasarkan penelitian Dwi dan Setyaningrum, dari 18 kader posyandu di empat kelurahan yang berada di wilayah kerja Puskesmas Setabelan dan setelah mengikuti pelatihan tentang Pembuatan MP-ASI Lokal dengan Bahan Dasar BMC (Bahan Makanan Campuran) untuk balita pada Kader Posyandu di Wilayah Kerja Puskesmas Stabelan Surakarta, terdapat empat kader posyandu telah mempraktekkan resep-resep MPASI lokal yang diberikan selama pelatihan $(22,22 \%)$. Dari data tersebut tersebut dapat disimpulkan bahwa terdapat peningkatan keterampilan kader(11). Hal ini sesuai dengan pendapat Purnawan bahwa melalui pelatihan yang harapkan PMT yang diberikan di Posyandu menjadi lebih bermutu dan bernilai gizi tinggi(12).

\section{SIMPULAN DAN SARAN}

Terdapat pengaruh penggunaan buku saku Kelompok Pendukung Ibu tentang permasalahan pemberian ASI pada aspek pengetahuan dan keterampilan motivator Kelompok Pendukung Ibu.

Saran bagi dinas kesehatan agar dapat mengembangkan pelatihan untuk motivator sebagai penyegaran sehingga meningkatkan pengetahuan dan ketrampilan motivator dalam permasalahan pemberian ASI. Bagi Puskesmas diharapkan dapat memantau dan memberikan penyuluhan bagi para motivator untuk tetap melakukan kegiatan kelompok pendukung Ibu.

\section{RUJUKAN}

1. Keputusan Menteri Kesehatan Republik Indonesia Nomor 450/Menkes/SK/IV/ 2004 tentang Pemberian Air Susu Ibu (ASI) Secara Eksklusif pada Bayi di Indonesia [internet]. 2014 [cited 2014 Oktober 23]. Available from: http://aimi-asi.org/wp-content/ uploads/2013/01/10-kepmenkes-450.pdf.

2. Dinkes Bantul. Profil Dinas Kesehatan Kabupaten Bantul 2013. Dinas Kesehatan Kabupaten Bantul; 2013.

3. Hasan A. Kamus Besar Bahasa Indonesia. Jakarta: Balai Pustaka; 2003.

4. Arikunto S. Prosedur Penelitian Suatu Pendekatan Praktik. Jakarta: Rineka Cipta; 2006.

5. Artiwi T. Pengaruh Pemberian Buku Saku Tentang Jajanan Sehat Terhadap Tingkat Pengetahuan Jajanan Sehat Pada Murid Kelas V di Sekolah Dasar Negeri Glagah, Kelurahan Warungboto, Kecamatan Umbulharjo, Kota Yogyakarta. Yogyakarta: Fakultas Kesehatan Masyarakat Universitas Ahmad Dahlan; 2011.

6. Maryani T. Analisis Kinerja Motivator Menyusui dalam Mengelola Kelompok Pendukung Ibu (KPIbu) sebagai Upaya Peningkatan Pemberian ASI Eksklusif di Kabupaten Bantul Provinsi Daerah Istimewa Yogyakarta. Semarang: MIKM Undip; 2011.

7. Notoatmodjo S. Pendidikan dan Perilaku Kesehatan. Jakarta: Rineka Cipta; 2003.

8. Bensley F. Metode Pendidikan Kesehatan Masyarakat. Jakarta: EGC; 2009.

9. Evi H. Penggunaan Media Kata Bergambar Dalam Upaya Meningkatkan Kualitas Pembelajaran Membaca dan Menulis Permulaan di Kelas I Sekolah Dasar. Jurnal penelitian dan pendidikan. 2008;5(2):78-87.

10. Departemen Kesehatan R.I. Modul Analisis Sistem Penilaian/Pengukuran Mutu Pelayanan Kesehatan Dasar. Jakarta: Dirjen Binkesmas; 1997.

11. Dwi Sarbini, Setyaningrum Rahmawati. Pelatihan membuat MP-ASI lokal dengan bahan dasar BMC (bahan makanan campuran) untuk balita pada kader posyandu di wilayah kerja Puskesmas Stabelan Surakarta. Surakarta: Universitas Muhamadiyah Surakarta; 2008.

12. Purnawan. Kader Dalam Program Usaha Perbaikan Gizi Keluarga Kelurahan, Kemampuan Dan Popularitasnya. Prosiding Simposiu Pangan Dan Gizi Serta Konggres IV perhimpunan Peminaan Pangan Dan Gizi; 1990. 